\title{
Decision support information and analytical technology in discharge military personnel employment
}

\author{
Mykhailo Medvid ${ }^{1, *}$, Peter Ivashchenko ${ }^{2, * *}$, Igor Britchenko ${ }^{3, * * *}$, Iryna Trubavina ${ }^{1, * * * *}$, and Volodymyr Liutyi ${ }^{1, \dagger}$ \\ ${ }^{1}$ National Academy of the National Guard of Ukraine, 3 Zakhysnykiv Ukrainy Sq., Kharkiv, 61001, Ukraine \\ ${ }^{2}$ V. N. Karazin Kharkiv National University, 4 Svobody Sq., Kharkiv, 61022, Ukraine \\ ${ }^{3}$ State Higher Vocational School Memorial of Prof. Stanislaw Tarnowski in Tarnobrzeg, 50 Henryka Sienkiewicza Str., 39-400 \\ Tarnobrzeg, Poland
}

\begin{abstract}
The research material proposes the use of decision support information-analytical technology in discharge military personnel employment, which, in contrast to the usual processing of survey results, makes it possible to obtain more information for decision-making. Adherence to such an approach in the development of public administration mechanisms increases the likelihood that in the case of their implementation in the country there will be positive changes, as they will indirectly take into account the availability of necessary resources. Information and analytical technology to support decisions in the field of labor economics substantiates the development of the example of discharged military personnel social welfare. According to the content, the developed decision support information-analytical technology in the field of labor economics provides for the following components: formation of social protection mechanisms; development of a questionnaire on the use of the appropriate mechanism; statistical analysis of survey results (generation of empirical distributions of answers to questions relative frequencies; comparison of answers medians; correspondences analysis; factor analysis; analysis of hierarchies); meaningful interpretation; decision making.
\end{abstract}

\section{Introduction}

Labor is a complex and multifaceted phenomenon that plays a particularly important role both in the life of society and the individual, because this very concept is inseparable from human life. By changing the environment in the process of work and adapting it to their needs, people not only ensure their existence, but also create conditions for the development and progress of society. Labor is one of the most important forms of self-expression, selfactualization and human selfimprovement.

Military service is also a type of labor, the problems of which are devoted to many scientific studies. For example, the conscription forces young men to serve in the military, irrespective of their opportunity costs. As Paul Bingley, Petter Lundborg and Stéphanie Vincent Lyk-Jensen say "The opportunity costs of conscription are borne by men with the best labor market prospects" [1].

During hostilities, the number of servicemen who retire and have to apply to public employment service centers to find a new job. A significant part of this category of people has the desire and ability to create their own business and do business. However, in most of them the relevant competencies are not developed.

\footnotetext{
*e-mail: medvidmm@ukr.net

**e-mail: ipaplin7@gmail.com

***e-mail: trubavina@gmail.com

****e-mail: ibritchenko@gmail.com

†e-mail: liutyy@ukr.net
}

In order to prevent the growth of social tension in society, to employ of this category of people, and to ensure the creation of new jobs for them, mechanisms for public management of human resources with military competencies, including training, retraining and advanced training need to be defined. According to Henry J. Meyer and Erwin O. Smigel "fully understand this joblessness, it is necessary to study the types of unemployed veteran" [2].

Ignoring this problem, increasing the level of poverty of the Ukraine population, deteriorating socio-economic conditions of human development at the end of hostilities may increase migration, in particular, the part of the population with developed military competencies, as well as lead to creation of private military companies in Ukraine that deliver combat services to other states.

\section{Intent of the research justification}

Based on the needs of society, the development (improvement) of mechanisms of retired military personnel social welfare is substantiated, as well as determined their advantages and disadvantages. These include [3, 4]:

- the state management mechanism of development of the military instructor social institution;

- the state management mechanism of ex-servicemen retraining and their support in creation their own business and running business; 
- the state management mechanism of social welfare of ex-servicemen through rehabilitation and employment abroad.

Decision-making on the allocation of resources for the functioning of the above mechanisms is a difficult task and it requires the development of information and analytical technology to support decisions on social welfare of military personnel. Among the publications there are many devoted to decisions support information and analytical technologies in the field of labor economics [5, 6]. However, their use to solve this problem is unacceptable.

\section{Results and discussion}

In order to determine the advantages in the functioning of one or another of the mechanisms suggested above, a questionnaire for military personnel was developed. The servicemen were invited to act as an expert and evaluate the options for the formation (development) of social welfare mechanisms for retired servicemen.

We developed a military personnel questionnaire to determine the advantages in the functioning of one or another of the mechanisms suggested above. And we invited the acting servicemen to expert and evaluate the options for the formation (development) of social welfare mechanisms for the retired military personnel.

Scenario № 1, The type of mechanism is "the state management mechanism for development of the military instructor social institution". It is characterized by the influence on the formation of the public good "military security" through the human resources for combat activities formation and development (military-patriotic educated youth, the formation in another state population the military competencies (participation in the officers' training, including reserve officers' training program, NCO training program, in the developing of primary military competencies within "The Motherland Defense" subject in secondary schools and other subjects in military lyceums and lyceums with enhanced military and physical training)). The advantage of this type is that it requires minimum costs.

Scenario № 2, The type of mechanism is "the state management mechanism for ex-servicemen retraining and their support in creation their own business and running business". It is characterized by affecting the state socioeconomic development, creating new enterprises that leads to the creation of new jobs that can be allocated to exservicemen, including those who became disabled while participating in hostilities and affecting the formation of the public good "military security" with the deductions. But there is and disadvantage of this type as it requires significant funding.

Scenario № 3, The type of mechanism is "the state management mechanism for social welfare of ex-servicemen through rehabilitation and employment abroad". It is characterized by affecting the reduction of social tensions in society by reducing the cost of social welfare, reducing unemployment (used in the absence of sufficient conditions for the functioning of mechanisms №
1 and № 2, or when it is impossible cover all persons in need of such social welfare). But there is and disadvantage of this type as there is a threat to the State secrecy and loss of human resources by the state, which can be used in the future in combat operations.

Scenario № 4, The type of mechanism is "there is no need to develop any of these mechanisms". It is characterized in, that the shortcomings of social adaptation of servicemen traditional institutional mechanisms are explained by foreign scientists mainly for two main reasons. First, they respond to challenges rather than anticipate them, and second, the traditional system turns a serviceman into a passive recipient of benefits and services, a kind of "gift set" from the State.

The servicemen evaluated the proposed options on a ten-point scale from 1 - "not important" to 10 - "very important" in response to questions:

1) provided that all the proposed opportunities exist what exactly did you use when you were released to the reserve (according to priorities)?;

2) evaluate each of the proposed options in terms of the need to form a public good "military security";

3) evaluate each of the proposed options in terms of the need for economic development of the state;

4) evaluate each of the proposed options in terms of the need to ensure the security of the state as a whole (social, economic, military, demographic, State secrecy);

5) provided that all the proposed options exist, predict the quality of implementation of each in our country;

6) estimate the cost of the state for each of the options (10 - the least, 1 - the most).

$$
X=\left(x_{n k l}\right),
$$

where $x_{n k l}$ - the number of points awarded by the serviceman by number $n(n=1, \ldots, 40)$; focusing on the criterion $k(k=1, \ldots, 6)$; in relation to the choice of specialty $l$.

The following criteria were used:

$C 1$ - the ability to choose any of the four mechanisms;

$C 2$ - the need for the formation of the public good "military security";

$C 3$ - economic development of the state;

$C 4$ - ensuring state security;

$C 5$ - an idea of the quality of each of the four mechanisms implementation;

C6 - government spending on the implementation of each mechanism.

The purpose of the application of the criteria is to link the solution of the problem of choosing the mechanism to the state and professional self-determination for further employment. The following professions were chosen: instructor; entrepreneur; mercenary; also, the fourth variant is considered - not professionally defined.

Let's perform a statistical analysis of the criteria. To do this, we regroup the data of the matrix $X$ by combining the columns of occupations into one for each criterion. We obtain a matrix 


$$
Y=\left(y_{i j}\right), i=1, \ldots, 160 ; j=1, \ldots, 6 .
$$

Diagrams (figures 1-6) of empirical distribution of relative frequencies of responses according to the criteria related to the mechanisms of state management for military personnel social welfare on a ten-point scale.

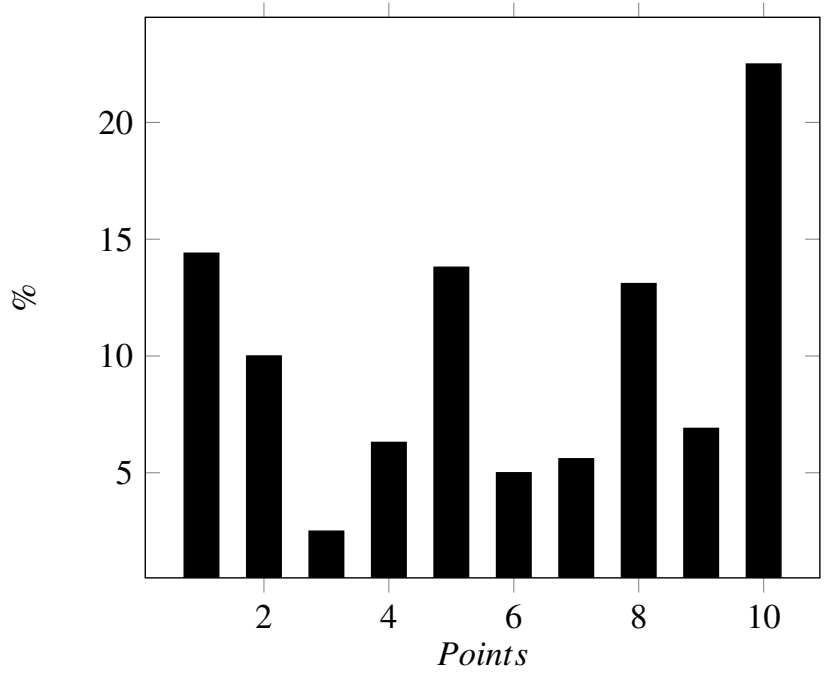

Figure 1. Criteria $\mathrm{C} 1$

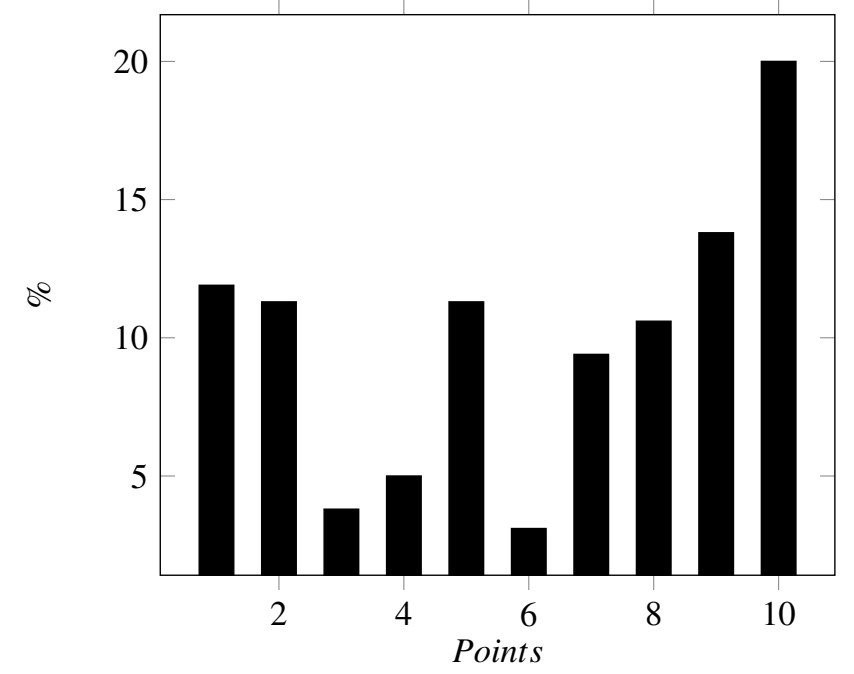

Figure 2. Criteria C2

In figures 1-6 it is presented the empirical distribution of the results of a survey of 40 retired servicemen (sample size is equal to 160), according to 6 criteria provided that the specialties are combined on a ten-point scale.

The following can be said about the peculiarities of the six given empirical criteria allocating.

Despite the presence of significant differences in the answers, they are characterized by categorical of answers for the lowest and highest scores. For example, when it is asked about the possibility of choosing any of the four specialties, points 1 and 10 were asked by $14.4 \%$ and $22.5 \%$

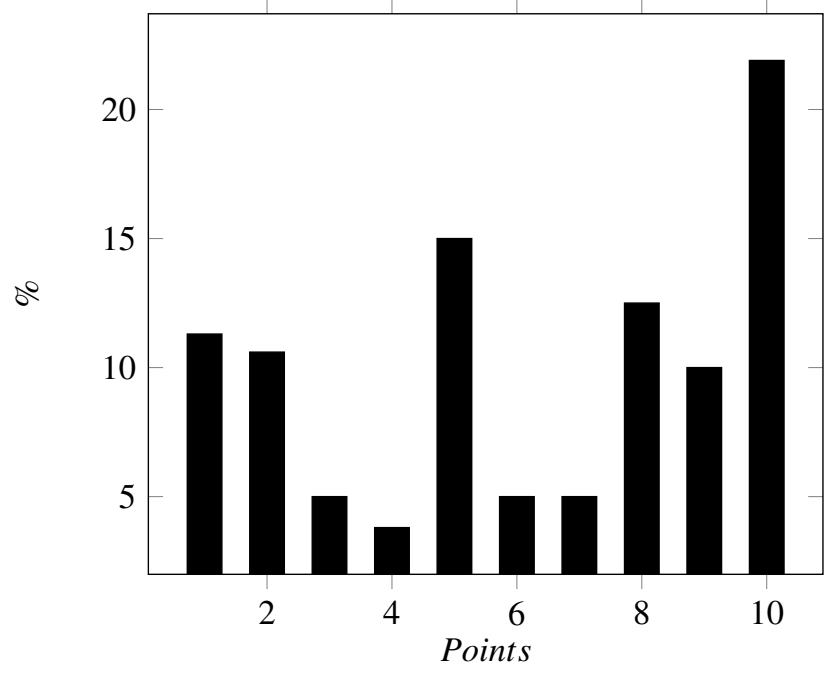

Figure 3. Criteria C3

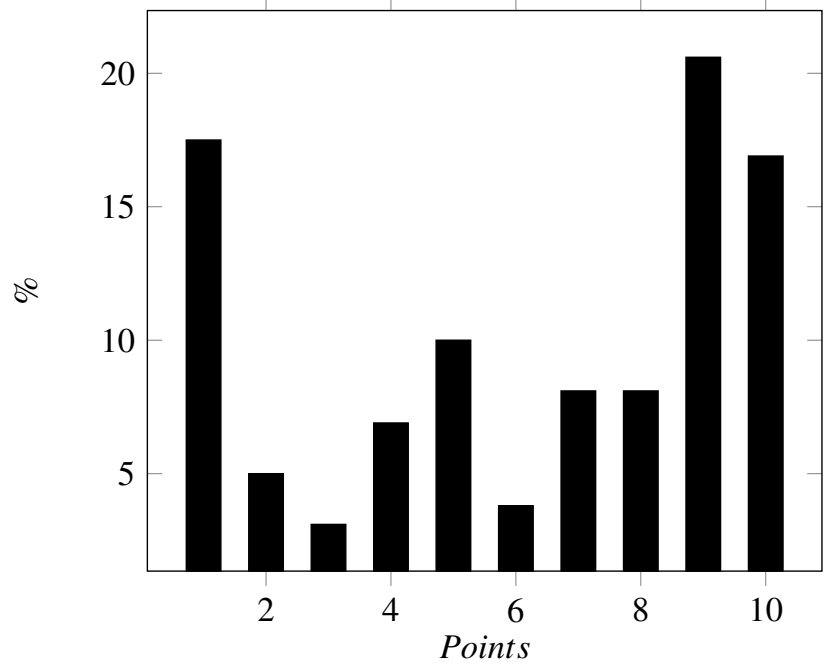

Figure 4. Criteria $\mathrm{C} 4$

of respondents (figure 1). Points 1 and 10 were given by $11.9 \%$ and $20 \%$ of respondents, realizing the need to form a public good "military security" (figure 2). Points 1 and 9 were given by $17.5 \%$ and $20.6 \%$ of respondents, in answers to questions about state security (figure 4).

It should be noted that there was a significant percentage of respondents with neutral responses (5 points). So, 5 points were given by $15 \%$ of respondents by criterion $C 3$ (figure 3), $14.4 \%$ of respondents by criteria $C 5, C 6$. The significance of the neutral nature of the answers to the criteria can be verified using Student's t-test or by its non-parametric alternative - the Kolmogorov-Smirnov criterion $[7,8]$.

A complete description of the median responses of servicemen comparison is given in table 1 .

We advance a number of hypotheses that the medians $\operatorname{Me}\left(y_{*, j 1}\right), M e\left(y_{*, j 2}\right)$ do not differ in pairs by $5 \%(p=0.05)$. 


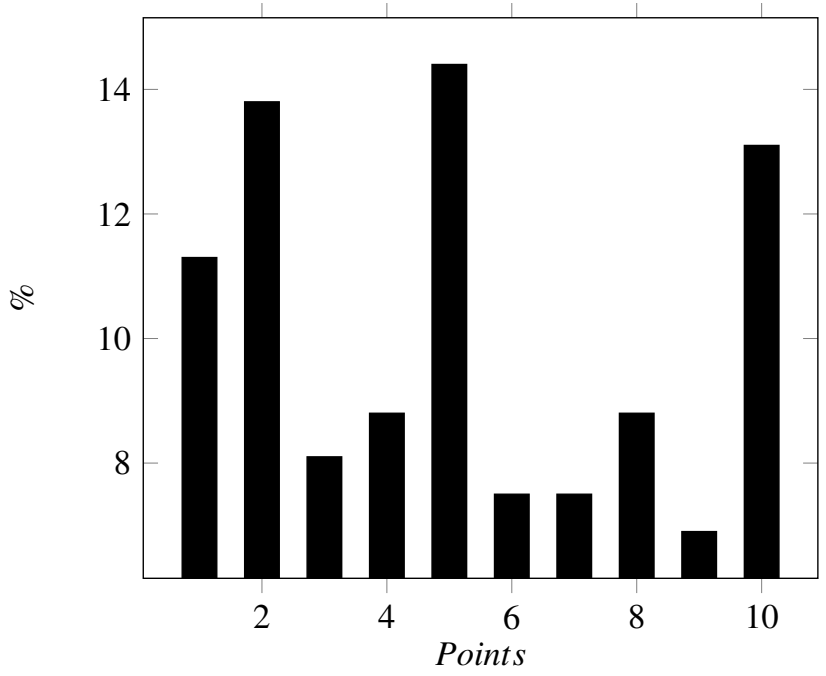

Figure 5. Criteria $C 5$

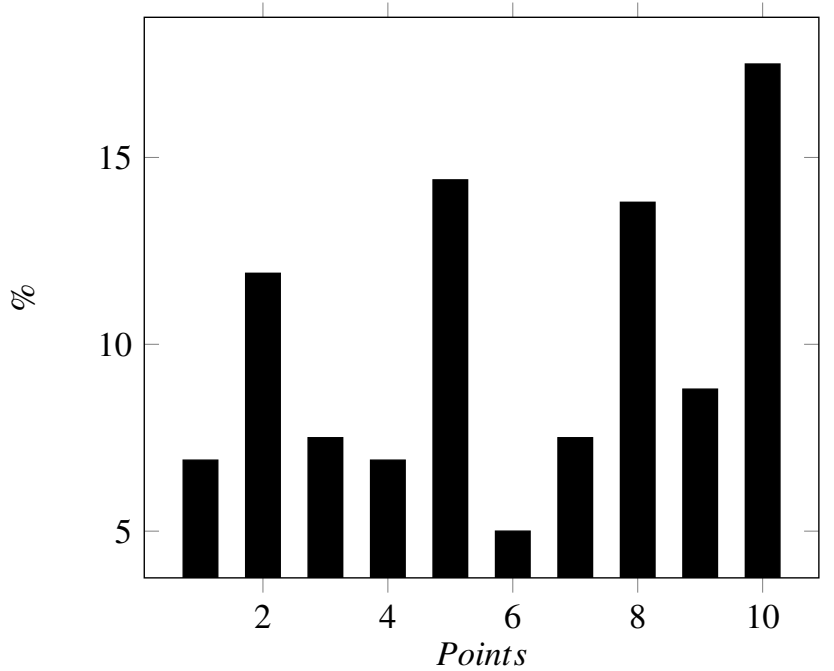

Figure 6. Criteria $C 6$

That is:

$$
\begin{aligned}
& H_{0}: \operatorname{Me}\left(y_{*, j 1}\right)-\operatorname{Me}\left(y_{*, j 2}\right)=0, \\
& H_{1}: \operatorname{Me}\left(y_{*, j 1}\right)-\operatorname{Me}\left(y_{*, j 2}\right) \neq 0
\end{aligned}
$$

where $j 1 \neq j 2, j 1, j 2=1, \ldots, 6$.

Since the variables $C$ are measured on an ordinal scale, to test hypothesis (3-4) we use the nonparametric Wilcoxon test $[8,9]$.

The averages and the magnitude of variation for the vectors of the statistical population given by the matrix $\mathrm{Y}$ are calculated and constructed in the program STATISTICA. The results are presented graphically in figure 7 .

We apply correspondence analysis [9].

In the table 2 it is shown a fragment of the frequency matrix obtained by the transition from frequencies (results of questionnaire processing) to particulars.

According to the table, using the tools of associative (corresponding, relevant) analysis [9], we establish asso-
Table 1. The results of variable check $C 1, \ldots, C 6$ by Wilcoxon test (calculated by the authors)

\begin{tabular}{lll}
\hline Pairs variates & $\boldsymbol{W}$ & $\boldsymbol{p}$-value \\
\hline$C 1$ \& $C 2$ & 2032.5 & 0.4474 \\
$C 1$ \& $C 3$ & 3013 & 0.5503 \\
$C 1$ \& $C 4$ & 3371.5 & 0.4956 \\
$C 1$ \& $C 5$ & 6001.5 & $\mathbf{0 . 0 2 6 2}$ \\
$C 1$ \& $C 6$ & 5700 & 0.9445 \\
$C 2$ \& $C 3$ & 2287.5 & 0.6950 \\
$C 2$ \& $C 4$ & 2815 & 0.7784 \\
$C 2$ \& $C 5$ & 5749.5 & $\mathbf{0 . 0 0 2 0}$ \\
$C 2$ \& $C 6$ & 5544.5 & 0.6186 \\
$C 3$ \& $C 4$ & 2999 & 0.7270 \\
$C 3$ \& $C 5$ & 4528 & $\mathbf{0 . 0 1 8 5}$ \\
$C 3$ \& $C 6$ & 5156 & 0.7570 \\
$C 4$ \& $C 5$ & 5922 & $\mathbf{0 . 0 0 5 9}$ \\
$C 4$ \& $C 6$ & 5487.5 & 0.7004 \\
$C 5$ \& $C 6$ & 3398.5 & $\mathbf{0 . 0 3 3 2}$ \\
\hline
\end{tabular}

ciative links between criteria and specialties. The results are obtained by analyzing figure 8 .

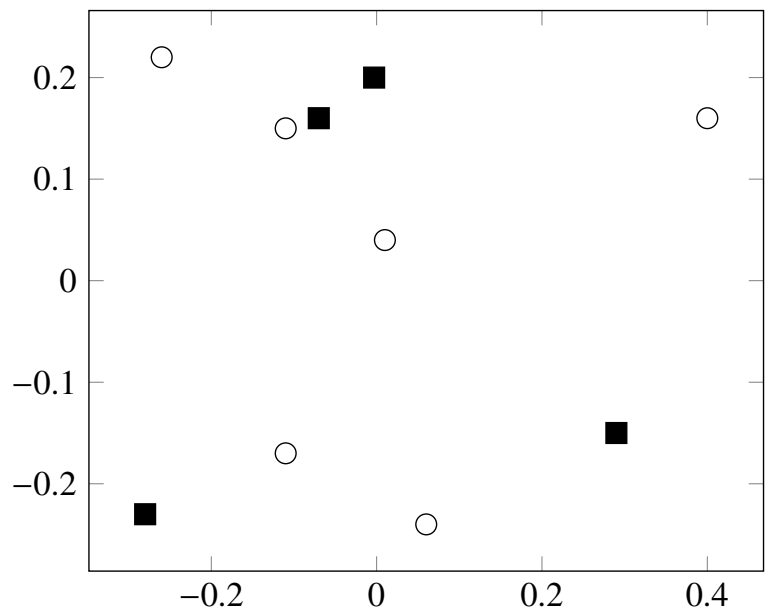

Figure 7. Position of rows (criteria, $C_{I}$ ) and columns frequency coordinates (professions, $J_{l}$ )

Table 2. Fragment of two-input frequency matrix $\left(C_{i}\right.$ - criteria, $i=1, \ldots, 6 ; J_{l}$ - profession; $\left.l=1, \ldots, 4\right), \%$

\begin{tabular}{lllll}
\hline & $\boldsymbol{J 1}$ & $\boldsymbol{J 2}$ & $\boldsymbol{J 3}$ & $\boldsymbol{J 4}$ \\
\hline $\boldsymbol{C} 1$ & 3.6 & 2.7 & 3.6 & 3.6 \\
$\boldsymbol{C} 2$ & 1.8 & 3.6 & 5.4 & 4.5 \\
$\boldsymbol{C} 3$ & 6.3 & 0.9 & 5.4 & 3.6 \\
$\boldsymbol{C} 4$ & 2.7 & 2.7 & 3.6 & 4.5 \\
$\boldsymbol{C} 5$ & 7.2 & 5.4 & 3.6 & 4.5 \\
$\boldsymbol{C 6}$ & 5.4 & 6.3 & 5.4 & 3.6 \\
\hline
\end{tabular}

The extended correlation matrix for variables $C 1-C 6$ has the form given in table 3 .

The close (significant) positive relationship between the variables $C 1-C 6$ (the values of the pairwise correlation coefficients are equal to or greater than 0.7 ) is indicated in 


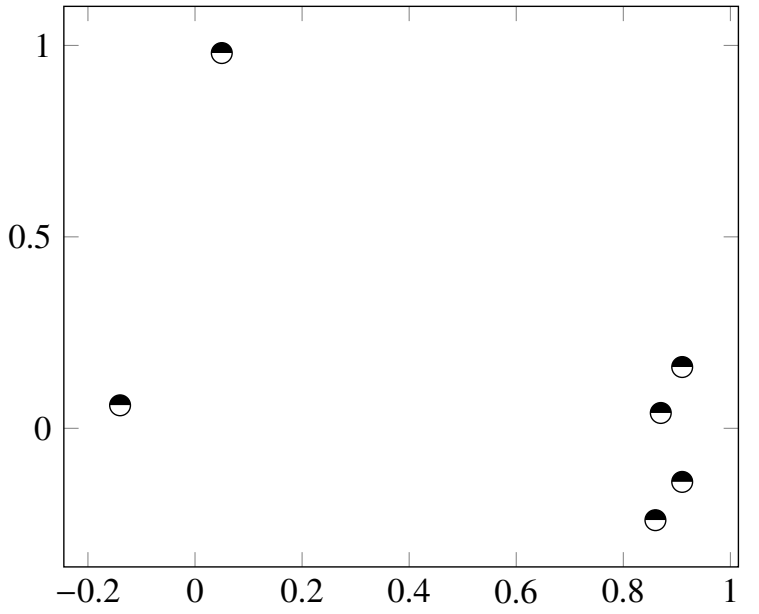

Figure 8. Representation of criteria $C 1, \ldots, C 6$ in the space of factors $F 1$ and $F 2$ after rotation) and columns frequency coordinates (professions, $J_{l}$ )

Table 3. Extended correlation matrix for variables $\left(C_{1}-C_{6}\right)$

\begin{tabular}{lllllll}
\hline Criteria & $\boldsymbol{C 1}$ & $\boldsymbol{C 2}$ & $\boldsymbol{C 3}$ & $\boldsymbol{C} 4$ & $\boldsymbol{C 5}$ & $\boldsymbol{C 6}$ \\
\hline $\boldsymbol{C} 1$ & 1 & $\mathbf{0 . 7}$ & 0.6 & 0.6 & -0.1 & -0.2 \\
$\boldsymbol{C} 2$ & $\mathbf{0 . 7}$ & 1 & $\mathbf{0 . 7}$ & $\mathbf{0 . 8}$ & 0.2 & -0.2 \\
$\boldsymbol{C} 3$ & 0.6 & $\mathbf{0 . 7}$ & 1 & $\mathbf{0 . 8}$ & 0.1 & -0.2 \\
$\boldsymbol{C} 4$ & 0.6 & $\mathbf{0 . 8}$ & $\mathbf{0 . 8}$ & 1 & 0.2 & -0.3 \\
$\boldsymbol{C} 5$ & -.1 & 0.2 & 0.07 & 0.2 & 1 & 0.1 \\
$\boldsymbol{C} 6$ & -.2 & -0.2 & -0.2 & -0.2 & 0.1 & 1 \\
\hline
\end{tabular}

bold. The set of close relationships gives rise to the following structure (figure 9), that need to be studied further.

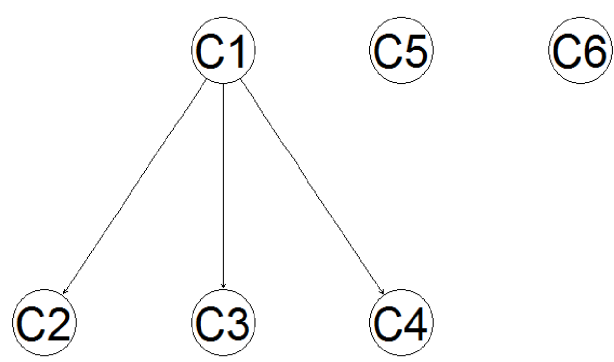

Figure 9. The structure of significant relationships between variables $C 1, \ldots, C 6$

Data analysis table 3 and figure 9 suggests the existence of three or four generalizing factors, which largely cover the percentage of the total variables $C 1, \ldots, C 6$ variance.

Using the method of factor analysis and taking into account the presence of a close correlation between the variables $C 1, C 2, C 3, C 4$ (see table 3), we build table 4 .

Table 4 presents the factor loads (pairwise correlation coefficients between $C_{i}$ and $F_{j}$ ), as well as the total variances of the factors and their fate. Sets of significant loads are highlighted in bold $(>0.7)$.
Table 4. Factor loads and their total variances with corresponding fractions

\begin{tabular}{llll}
\hline Variable & Factor $($ F1) & Factor $($ F2) & Factor $($ F3) \\
\hline C1 & $\mathbf{0 . 8 6}$ & -0.24 & 0.08 \\
C2 & $\mathbf{0 . 9 1}$ & 0.14 & 0.06 \\
C3 & $\mathbf{0 . 8 7}$ & 0.04 & 0.12 \\
C 4 & $\mathbf{0 . 9 1}$ & 0.16 & 0.13 \\
C5 & 0.05 & $\mathbf{0 . 9 8}$ & -0.05 \\
C6 & -.14 & -0.06 & $\mathbf{- 0 . 9 9}$ \\
\hline
\end{tabular}

Factor loads are obtained by the method of principal components with subsequent oblique rotation (Varimax normalized) [10].

Based on the comparative analysis method of public administration experience [3] and using the method of analysis of Saati hierarchies [11], we build a scheme of hierarchies for choosing the option of social welfare of servicemen discharged to reserve (figures 10, 11).

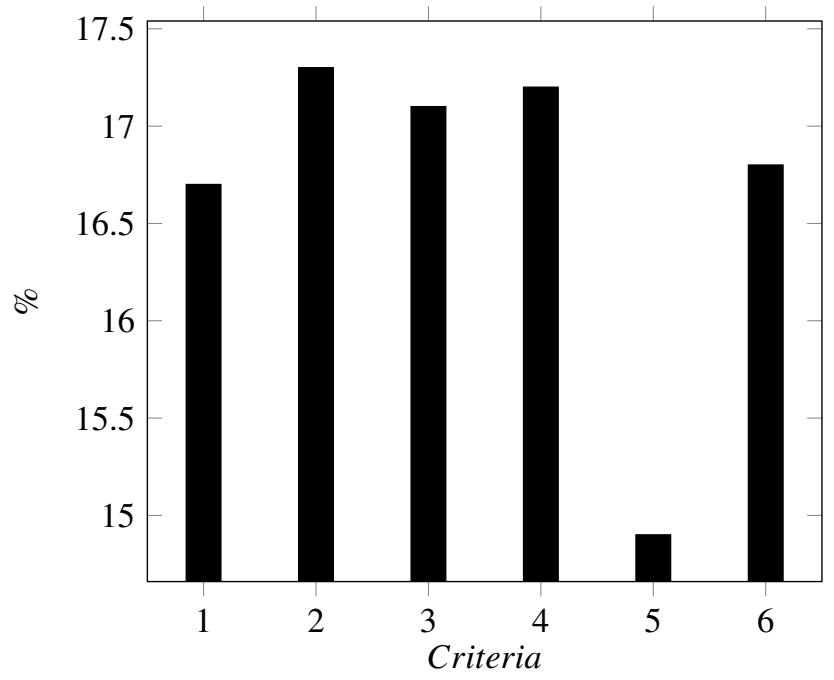

Figure 10. The structure of military personnel preferences of by criteria

The developed decision support information-analytical technology in the field of labor economics within its content provides the following components:

1. Establishment of social welfare mechanisms.

2. Development of a questionnaire regarding the use of the appropriate mechanism.

3. Statistical analysis of survey results:

- generation of empirical distributions of answers to questions relative frequencies;

- comparison of answers medians;

- correspondences analysis;

- factor analysis;

- analysis of hierarchies.

4. Meaningful interpretation.

5. Decision making. 


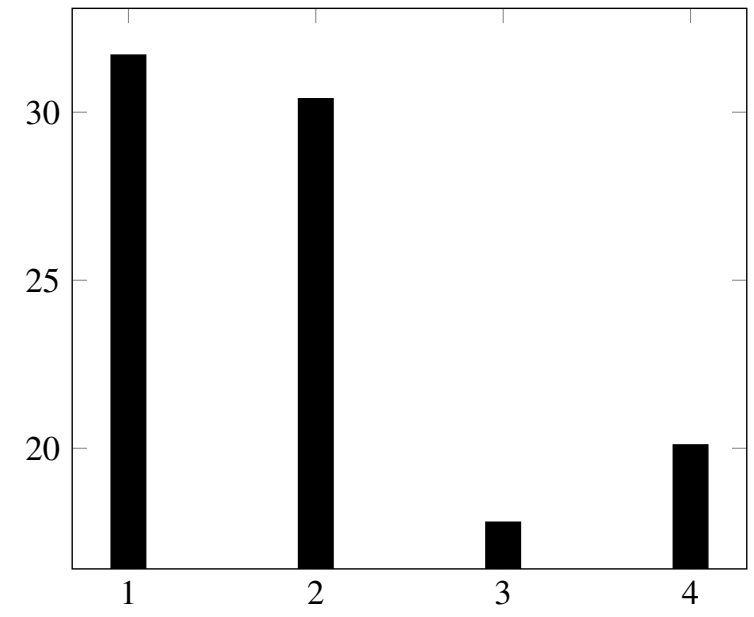

Figure 11. The structure of military personnel preferences by alternatives ( 1 - instructor; 2 - entrepreneur; 3 - mercenary; 4 not professionally defined)

According to the results of data processing it is established that:

1. Respondents prefer such mechanisms as the state management mechanism for development of the military instructor social institution; and the state management mechanism of ex-servicemen retraining and their support in creation their own business and running business (figure 11). This is important information for the resources' allocation for the operation of these mechanisms.

2. Despite the fact that according to figure 10 criteria $C 2, C 3$ and $C 4$ are equivalent, among them the most important in the opinion of respondents is $C 2$ criteria. This criterion is the need to form a public good "military security", because it has the largest number of links with others (figure 9). This is important information that shows that the servicemen who took part in the survey are worried about the fate of the state and they are patriotic.

3. The relatively low value of $C 5$ criterion that means the idea of the quality of implementation of each of the mechanisms indicates distrust of the military in the implementation of socio-economic policy in the state (figure 10). This is important information for further research in this area.

Thus, the implementation of the developed decision support information-analytical technology in the field of labor economics makes it possible to obtain more information for decision-making in comparison with the usual processing of survey results.

\section{Conclusion}

The research material suggests the use of decision support information-analytical technology in discharge military personnel employment developed by its authors. And, in contrast to the usual processing of survey results, it makes possible to obtain more information for decisionmaking. Adherence to such approach in the development of public administration mechanisms, it increases the likelihood that in the case of their implementation in the country the positive changes will be expected, as they will indirectly take into account the availability of necessary resources. Information and analytical technology to support decisions in the field of labor economics substantiates the development of the example of discharged servicemen social welfare.

According to the content, the developed decision support information-analytical technology in the field of labor economics provides for the following components: formation of social protection mechanisms; development of a questionnaire on the use of the appropriate mechanism; statistical analysis of survey results (generation of empirical distributions of answers to questions relative frequencies; comparison of answers medians; correspondences analysis; factor analysis; analysis of hierarchies); meaningful interpretation; decision making.

According to the results of data processing it is established that:

1. Respondents prefer such mechanisms as the state management mechanism for development of the military instructor social institution; and the state management mechanism for ex-servicemen retraining and their support in creation their own business and running business. This is important information for the resources' allocation for the operation of these mechanisms.

2. The servicemen who took part in the survey are worried about the fate of the state and they are patriotic.

3. There is a distrust of the military personnel in the implementation of socio-economic policy in the state. This is an important information for further research in this field.

\section{References}

[1] P. Bingley, P. Lundborg, S.V. Lyk-Jensen, Journal of Labor Economics 38, 39 (2020)

[2] H.J. Meyer, E.O. Smigel, American Journal of Sociology 56, 341 (1951)

[3] M.M. Medvid, Law and Honor 2, 107 (2020)

[4] M.V. Zverev, Public administration studies 3 (2019)

[5] Y. Smith, Social Service Review 88, 407 (2014)

[6] L. Garicano, P. Heaton (2010)

[7] T. Cleff, Applied Statistics and Multivariate Data Analysis for Business and Economics (Springer, 2019)

[8] NIST/SEMATECH, e-Handbook of Statistical Methods (2013), https://www.itl.nist.gov/ div898/handbook/

[9] E.J. Beh, Correspondence Analysis: Theory, Practice and New Strategies (John Wiley \& Sons Ltd, 2014) 
[10] A.C. Weide, A. Beauducel, Frontiers in Psychology 10, 645 (2019)
[11] T.L. Saati, Fundamentals of Decision Making and Priority Theory with the Analytic Hierarchy Process (RWS, 1994) 